\title{
Overcoming the Constraints of Anti-HIV/CD89 Bispecific Antibodies That Limit Viral Inhibition
}

\author{
Xiaocong Yu, ${ }^{1,2}$ Mark Duval, ${ }^{1}$ Melissa Gawron, \\ Marshall R. Posner, ${ }^{1,2}$ and Lisa A. Cavacini ${ }^{1,2}$ \\ ${ }^{1}$ Department of Medicine, Beth Israel Deaconess Medical Center, Boston, MA 02215, USA \\ ${ }^{2}$ Harvard Medical School, Boston, MA 02215, USA \\ Correspondence should be addressed to Xiaocong Yu; xiaocong.yu@umassmed.edu \\ and Lisa A. Cavacini; lisa.cavacini@umassmed.edu
}

Received 30 November 2015; Revised 9 May 2016; Accepted 22 May 2016

Academic Editor: Leandro J. Carreño

Copyright (C) 2016 Xiaocong Yu et al. This is an open access article distributed under the Creative Commons Attribution License, which permits unrestricted use, distribution, and reproduction in any medium, provided the original work is properly cited.

\begin{abstract}
Innovative strategies are necessary to maximize the clinical application of HIV neutralizing antibodies. To this end, bispecific constructs of human antibody F240, reactive with well-conserved gp41 epitope and antibody 14A8, reactive with the IgA receptor (CD89) on effector cells, were constructed. A F240 $\times 14$ A8 bispecific single chain variable region (scFv) molecule was constructed by linking two scFvs using a conventional GGGGS linker. Despite immunoreactivity with HIV gp41 and neutrophils, this bispecific scFv failed to inhibit HIV infection. This is in sharp contrast to viral inhibition using a chemical conjugate of the Fab of these two antibodies. Therefore, we constructed two novel Fab-like bispecific antibody molecules centered on fusion of the IgG1 CH1 domain or $\mathrm{CH1}$-hinge domain to the $\mathrm{C}$-terminus of $\mathrm{F} 240 \mathrm{scFv}$ and fusion of the kappa chain $\mathrm{CL}$ domain to the C-terminus of 14A8scFv. Both Bi-Fab antibodies showed significant ADCVI activity for multiple clade B and clade C isolates by arming the neutrophils to inhibit HIV infection. The approach presented in this study is unique for HIV immunotherapy in that the impetus of neutralization is to arm and mobilize PMN to destroy HIV and HIV infected cells.
\end{abstract}

\section{Introduction}

Notwithstanding the isolation of broadly neutralizing antiHIV-1 human antibodies [1], there remain a number of limitations for clinical applications, including global subtype coverage. One approach is to broadly target virus using conserved nonneutralizing domains on the HIV-1 Env and to target virus for destruction using noninfectable effector cells. It has been shown that Antibody-Dependent Cellular Cytotoxicity (ADCC) can be mediated by nonneutralizing antibodies and it has been shown to be higher in HIV controllers [2,3].

We previously demonstrated that a bispecific antibody, constructed by chemical conjugation of the Fab regions of F240 and the anti-CD89 (IgA receptor) antibody 14A8, promotes destruction of HIV by neutrophils [4]. F240 recognizes a highly conserved extracellular epitope (residues 598 to 604) on gp41 within cluster I and reacts with primary isolates from all clades of HIV-1 [5], similar to other cluster I antibodies. The majority of clades A, B, and C isolates in the HIV-1 sequence database have an identical peptide (amino acids 592 to 606), with the exception of clade D isolates, which have a consistent $\mathrm{L} 602 \mathrm{H}$ mutation. Our prior study supports the notion that broadly reactive, nonneutralizing antibodies, such as F240, could be used to "neutralize" HIV and might be a practicable novel therapeutic strategy for prevention and treatment of HIV infection. However, chemical conjugation for the construction of bispecific antibodies is associated with technical and large scale production issues.

To create and study different bispecific molecular constructs and promote a better production process, we have constructed bispecific antibodies using conventional linkers of scFv fragments as well as two novel Fab-like bispecific antibody structures. Further, we demonstrate that specific recombinant bispecific antibody structures effectively inhibit HIV infection. The results described here also report on the contribution of molecular structure of the bispecific antibody to maximal anti-HIV functional activity. 


\section{Materials and Methods}

2.1. Monoclonal Antibodies, Virus, and Cell Lines. Antibody F240, generated in our laboratory, binds to a broadly conserved domain of gp41 [5]. The 14A8 is a human anti-CD89 antibody that was generated in Medarex-Mouse human Ig transgenic mice [6]. The bispecific single chain (scFv) antibody expression vector pcDNA3.1 was from Invitrogen. The vectors of $\mathrm{pLC}-\mathrm{HuC} \kappa$ and $\mathrm{pHC}-\mathrm{HuC} \gamma 1$ for expressing $\mathrm{Bi}$ Fab antibodies were obtained from Dr. McLean [7] and were modified for expressing Fab-like bispecific antibodies. CHO$\mathrm{K} 1$ cells were from American Type Culture Collection. The following reagents were obtained through the AIDS Research and Reference Reagent Program, Division of AIDS, NIAID, NIH: SF162 (R5) from Dr. Jay Levy; BaL (R5) from Dr. Suzanne Gartner, Dr. Mikulas Popovic, and Dr. Robert Gallo; 93MW960 (clade C, R5) from Dr. Robert Bollinger and the UNAIDS Network for HIV; JR-FL (R5) from Dr. Irvin Chen; TZM-bl cells from Dr. John C. Kappes, Dr. Xiaoyun Wu, and Transzyme, Inc.; isolate 67970 (CXCR4) from Dr. David Montefiori.

2.2. Construction of Antibody F240 and $14 A 8$ scFv Molecules. Total RNA was isolated from F240 hybridoma cell line and then amplified the variable domain fragments of heavy chain $(\mathrm{VH})$ and light chain $(\mathrm{VL})$ using RT-PCR. The 14A8 variable domain fragments of $\mathrm{VH}$ and VL were directly amplified using 14A8 antibody gene plasmids as PCR template. A peptide (GGGGS) ${ }_{3}$ was used as a linker to assemble VH and VL together to form the F240scFv and $14 \mathrm{~A} 8 \mathrm{scFv}$ individually by overlap PCR.

2.3. Construction of Conventional F240 $\times 14 A 8$ Bis-scFv Antibody Plasmid and Establishing Stable Expressing Cell Lines. An F240 $\times 14$ A8 bispecific scFv antibody was constructed using a conventional structure. A DNA sequence that codes a short linker peptide consisting of glycine and serine residues (GGGGS) was designed to connect F240scFv and $14 \mathrm{~A} 8 \mathrm{scFv}$ by overlap PCR. The amplified Bi-scFv fragment was cloned into pcDNA3.1 vector utilizing the restriction sites of NheI and HindIII. The constructed plasmid was transfected into CHO cells with lipofectamine LTX (Invitrogen) using selection medium containing $1 \mathrm{mg} / \mathrm{mL}$ zeocin for at least two weeks. Limiting dilution at 1 cell per well was performed twice to obtain a stable cell line.

2.4. Constructing Plasmids of F240 $\times 14 A 8$ Bi-Fab and Establishing Stable Expression Cell Lines. A human IgG CH1 fragment or $\mathrm{CH} 1+$ hinge fragment was amplified by PCR from the human IgG1 heavy chain and c-myc plus 6XHis tags was assembled into the $3^{\prime}$ end. The F240scFv genes (as described above with linkers) were connected directly with these amplified fragments individually by overlap extensional PCR, and the PCR products were cloned into the IgG expressing vector (Dr. McLean) to replace the human IgG1 constant domain. Meanwhile, thel4A8scFv was cloned into the vector of pLC-HuCk using NheI/NotI sites which contained human kappa chain constant. Paired purified plasmids encoding the $14 \mathrm{~A} 8 \mathrm{scFv}-\mathrm{CL}$ versus $\mathrm{F} 240 \mathrm{scFv}-\mathrm{CH} 1$ or $14 \mathrm{~A} 8 \mathrm{scFv}-\mathrm{CL}$ versus
F240scFv-CH1-hinge were cotransfected into CHO-K1 cells in 6-well plates with lipofectamine LTX (Invitrogen Life Technologies). G418 (800 $\mu \mathrm{g} / \mathrm{mL})$ and puromycin $(10 \mu \mathrm{g} / \mathrm{mL})$ were used for selection of stable transfectants. The plates were screened using capture ELISA assay. The positive wells with top producing capacity were cloned by one-cell-perwell limiting dilution to establish the highest expressing cell clones. The expressed Bi-Fabs in culture supernatant were purified using protein L. Expression from the stable cell lines varied from a low expression of $1 \mu \mathrm{g} / \mathrm{mL}$ to $50 \mu \mathrm{g} / \mathrm{mL}$ depending on the tissue culture vessel used. Recovery of antibody following purification was similar to what we see using protein $G$ columns and IgG and efficiency was proportional to the amount of antibody applied to the column up to capacity.

2.5. Immunoreactivity of F240 and CD89 Components of BiFab Antibodies. To detect F240 reactivity, microplates were coated with recombinant gp41 (ectodomain aa 546-682 of $\mathrm{HxB} 2$ strain, Meridian) at $2 \mu \mathrm{g} / \mathrm{mL}$ in PBS overnight at $4^{\circ} \mathrm{C}$ followed by blocking with BSA blocking buffer plus $0.01 \%$ tween at room temperature for 2 hours. Bi-Fab samples were added at $1 \mu \mathrm{g} / \mathrm{mL}$ and serial dilutions were performed. Samples were incubated for 30 minutes followed by washing and incubation with HRP-conjugated protein L (Pierce). The human monoclonal F240 was run as a standard to determine relative reactivity of the F240-14A8 Bi-Fabs. After washing, $100 \mu \mathrm{L}$ of TMB substrate was added and incubated for 5 minutes. Reaction was stopped with $100 \mu \mathrm{L}$ of $1 \mathrm{M}$ phosphoric acid and plate was read on a plate reader at $450 \mathrm{~nm}$.

Immunoreactivity of 14A8 with CD89 was determined by flow cytometry. Neutrophils were isolated from peripheral blood of HIV seronegative donors using Ficoll-Hypaque gradient centrifugation and dextran sedimentation. PMNs were washed twice with PBS and resuspended at a concentration of $1 \times 10^{7} \mathrm{c} / \mathrm{mL}$ in HBSS containing 2.5\% FBS. $100 \mu \mathrm{L}$ of PMNs was mixed with $100 \mu \mathrm{L}$ of serial diluted Bi-Fab antibodies and incubated on ice for 30 minutes. Cells were washed twice with PBS followed by 30-minute incubation with FITC-labeled Goat anti-human Ig Kappa (Southern Biotechnology Associates). PMNs were washed and fixed in $1 \%$ paraformaldehyde and samples were acquired and analyzed using Guava 8HT and Incyte software. Live cells were gated based on forward and side scatter.

2.6. Antibody-Dependent Cell-Mediated Viral Inhibition (ADCVI). The ability of the antibody to arm neutrophils to inhibit HIV infection was measured as ADCVI activity of constructed bispecific antibodies using HIV grown in PHA stimulated PBMC $[8,9]$. Bispecific antibodies were tittered in 96-well plates with $50 \mu \mathrm{L}$ media. Neutrophils $(5 \times$ $10^{6}$ cells/well) were added and incubated with antibody for 10 minutes. PBMC productively infected with HIV-1 four days earlier were used as target cells and $5 \times 10^{5}$ infected cells were added to the antibody/effector cell mixture resulting in an $\mathrm{E}: \mathrm{T}$ ratio of $10: 1$. The $10: 1 \mathrm{E}: \mathrm{T}$ ratio was selected as the concentration of neutrophils that does not result in nonspecific inhibition of HIV by the neutrophils. After incubation for 4 hours, PHA stimulated PBMC $\left(2 \times 10^{6} /\right.$ well $)$ 
were added as indicator cells for measuring the surviving infectious virus and incubated for seven days in the presence of IL-2 and p24 quantitated by ELISA [10]. Linear regression analysis was used to determine $\mathrm{IC}_{50}$ values and Student's $t$-test was used to detect significance. Control wells included absent antibody, absent effector cells, and absent target cells to determine background release of virus, maximal production of virus, and whether PMN alone were infected, respectively. Experiments were repeated three times.

\section{Results}

A bispecific single chain antibody was made using a G4S peptide to link the F240 scFv with the $14 \mathrm{~A} 8 \mathrm{scFv}$. The bispecific scFv was found to bind to both gp41 (ELISA) and CD89 on neutrophils (flow cytometry). However, in contrast to our results using a chemical conjugate of Fab fragments of F240 and $14 \mathrm{~A}^{4}$, the F240 $\times 14 \mathrm{~A} 8$ biscFv antibody demonstrated limited ADCVI activity. At $10 \mu \mathrm{g} / \mathrm{mL}$, F2 $40 \times 14$ A 8 biscFv only inhibited $21-23 \%$ for JR-FL or 89.6 and failed to inhibit 93MW960 (data not shown). At this concentration, the chemical conjugate of F240 and 14A8 inhibited more than $50 \%$ for the isolates tested above. To ensure that this was not due to a donor specific neutrophil defect, the experiment was repeated on four separate occasions using different donor neutrophils. While the biscFv antibody failed to mediate ADCVI, a positive control anti-HIV b12 IgA or Alg8-IgA antibody known to mediate ADCVI inhibited infection ( $>40 \%$ at $10 \mu \mathrm{g} / \mathrm{mL}$ ), in the presence of neutrophil effectors as previously reported [10]. Furthermore, failure of the bispecific $\mathrm{scFv}$ to mediate ADCVI was not related to immunoreactivity of the anti-gp41 F240 component as the sequence of the epitope on gp41 recognized by this antibody is identical in all isolates used in this study.

In reviewing the structure of the chemically conjugated versus biscFv bispecific antibodies, we hypothesized that failure of the biscFv to mediate ADCVI yet retain immunoreactivity may be a function of the structural constraints of the smaller and less flexible biscFv as compared to the Fab. The longer Fab fragment with the first Fc constant domain $(\mathrm{CH} 1)$ and light chain constant (CL) may allow for more flexibility in bridging between the neutrophils and the infected cells. Therefore, we performed an innovative design to construct Fab-like bispecific antibodies. A dimeric or a tetrameric bispecific antibody was formed through the interchain disulfide bond between $\mathrm{CH} 1$ and $\mathrm{CL}$ or the $\mathrm{CH1}-$ hinge part and CL, respectively. The dimeric F240-CH1/14A8$\mathrm{CL}$ is designated as $\mathrm{F} 240 \times 14 \mathrm{~A} 8 \mathrm{Bi}-\mathrm{Fab}-\mathrm{A}$ and the tetrameric F240-CH1-hinge/14A8-CL as F240 $\times 14 \mathrm{~A} 8 \mathrm{Bi}-\mathrm{Fab}-\mathrm{B}$ and as depicted in Figure 1. Immunoreactivity of the F240 $\times 14 \mathrm{~A} 8$ Bi-Fab antibodies with HIV gp41 was determined by ELISA using F240 IgG1 antibody as the standard (Figure 2). Given that the epitope recognized by F240 is extremely conserved, it is expected that the Bi-Fab would react with the majority of isolates, with the exception of clade D. Both F $240 \times 14 \mathrm{~A} 8 \mathrm{Bi}$ Fab antibodies react with gp41 and due to bivalency for gp41 binding, higher level binding is seen with Bi-Fab-B and the F240 IgG1, as compared to Bi-Fab-A. Immunoreactivity of the 14A8 component of Bi-Fab antibodies with CD89 is

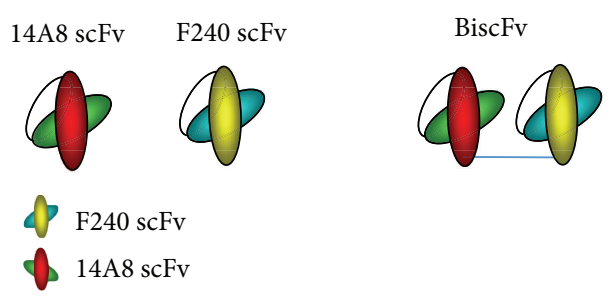

(a)
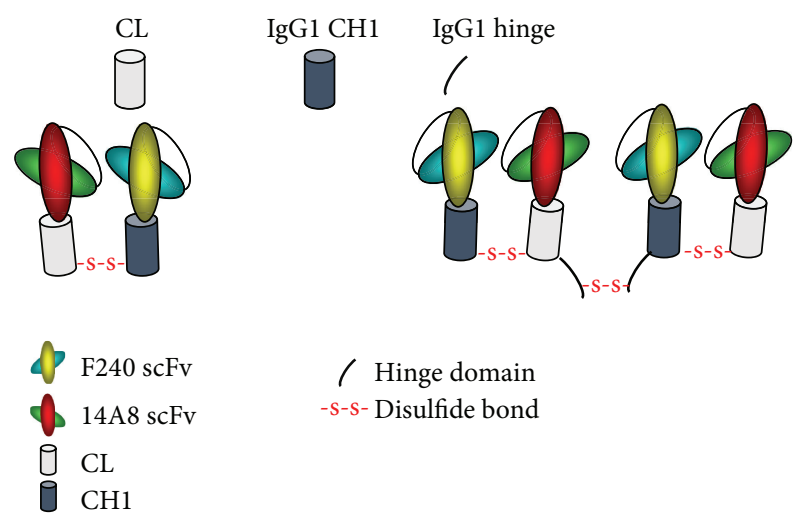

/ Hinge domain

-s-s- Disulfide bond

(b)

FIGURE 1: Schematic diagram of F240 $\times 14 \mathrm{~A} 8 \mathrm{Bi}-\mathrm{Fab}$ construction. The structure of the bispecific single chain antibody (biscFv) is depicted in (a) with the $\mathrm{VH}$ as either the green oval (14A8) or blue oval (F240) and the VL as the red oval (14A8) or yellow oval (F240). (b) represents the organization of the Bi-Fab.

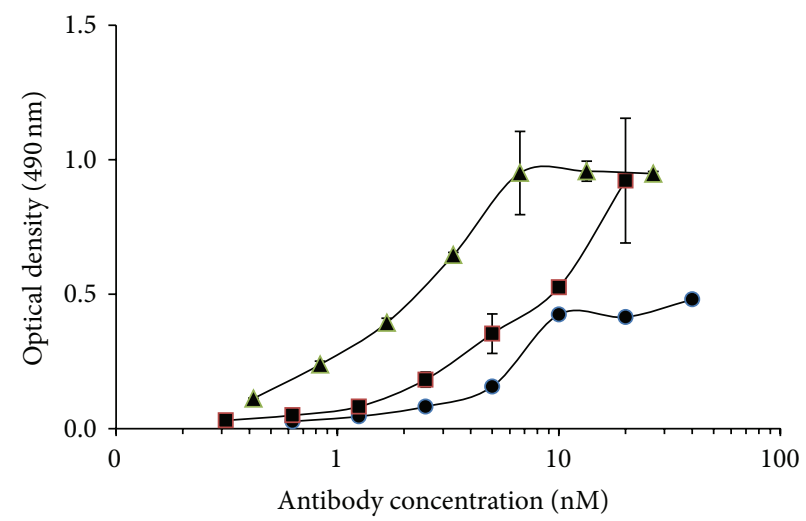

Figure 2: Immunoreaction of F240 $\times 14 \mathrm{~A} 8 \mathrm{Bi}-\mathrm{Fab}$ with gp41. Immunoreactivity of Bi-Fab antibody constructs with HIV antigen gp41. Antigen gp41 was coated at $2 \mu \mathrm{g} / \mathrm{mL}$ in PBS; the serial dilutions of Bi-Fab antibodies (Bi-Fab A, $\mathbf{0}$, and Bi-Fab B, $\mathbf{a}$ ) compared to that of serial dilutions of F240 antibody $(\mathbf{\Delta})$; the reaction was developed by HRP-conjugated protein L $(1: 20,000)$ and measured by optical density at $490 \mathrm{~nm}$. Results are representative of three different experiments and each experimental point is the mean \pm standard deviation of triplicate wells.

evident in Figure 3 using neutrophils from uninfected donors. Binding of both Bi-Fab antibodies occurs in a dose dependent manner and, similar to immunoreactivity with gp41, means that fluorescent intensity of Bi-Fab-B was greater than that seen for Bi-Fab-A. 


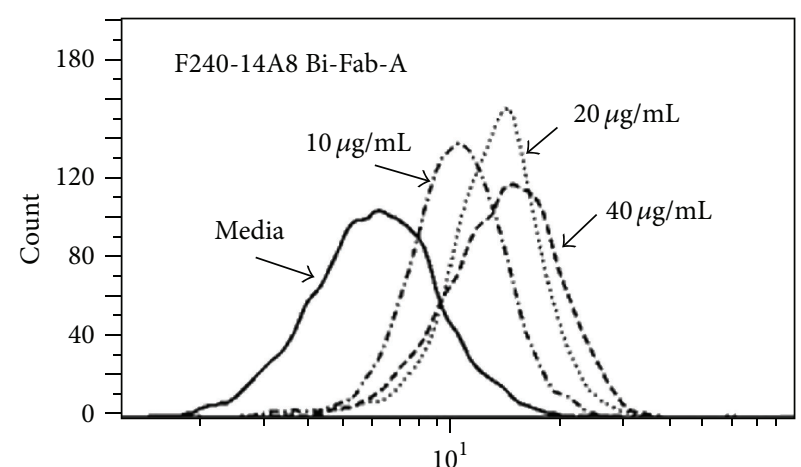

Fluorescence intensity

(a)

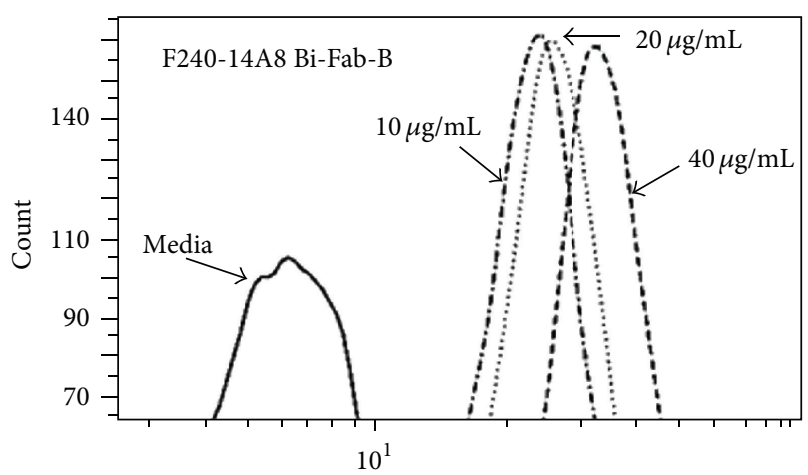

Fluorescence intensity

(b)

FIGURE 3: Binding affinity of F240 $\times 14 \mathrm{~A} 8 \mathrm{Bi}-\mathrm{Fab}$ with neutrophil through CD89. Neutrophils were washed twice with PBS and resuspended at a concentration of $1 \times 10^{7} \mathrm{c} / \mathrm{mL}$ in HBSS containing 2.5\% FBS. $100 \mu \mathrm{L}$ of neutrophils was mixed with $100 \mu \mathrm{L}$ of serial diluted Bi-Fab antibodies with Bi-Fab A in (a) and Bi-Fab B in (b). Cells were incubated with FITC-labeled goat anti-human Ig Kappa for 30 minutes. Neutrophils were fixed in $1 \%$ paraformaldehyde. Results are representative of four different neutrophil donors.

TABle 1: ADCVI activity of HIV-1 by F240 Bi-Fab antibody constructs.

\begin{tabular}{lcccc}
\hline & \multicolumn{4}{c}{$\mathrm{IC}_{50}(\mu \mathrm{g} / \mathrm{mL})^{\mathrm{a}}$} \\
& $\mathrm{BaL}$ & $\mathrm{JR}-\mathrm{FL}$ & $93 \mathrm{MW} 60$ & $\mathrm{~S} F 162$ \\
& Clade B, R5 & Clade B, R5 & Clade C R5 & Clade B, R5 \\
\hline Bi-Fab-A & $3.38 \pm 2.39$ & $0.04 \pm 0.04$ & $27.50 \pm 7.78$ & $15.69 \pm 5.49$ \\
Bi-Fab-B & $4.43 \pm 0.16$ & $35.85 \pm 5.87$ & $1.93 \pm 2.65$ & $0.22 \pm 0.04$ \\
& $p=0.60^{\mathrm{b}}$ & $p=0.01$ & $p=0.05$ & $p=0.06$ \\
Chemical $_{\text {bispecific }}{ }^{\mathrm{c}}$ & $4.35 \pm 1.2$ & $\mathrm{NT}^{\mathrm{d}}$ & $10.4 \pm 7.7$ & $10.7 \pm 2.9$ \\
\hline
\end{tabular}

${ }^{\mathrm{a}}$ The ADCVI activity was determined by $\mathrm{IC}_{50}$ that represents concentration $(\mu \mathrm{g} / \mathrm{mL})$ of Bi-Fab antibody constructs required for $50 \%$ inhibition of HIV. Results are from three separate experiments.

${ }^{\mathrm{b}}$ The $p$ value reflects the comparison of Bi-Fab-A versus Bi-Fab-B.

${ }^{c}$ Chemical conjugation of Fab fragments of F240 and 14A8 as described in [4].

${ }^{\mathrm{d}} \mathrm{NT}$ : not tested.

Importantly, both $\mathrm{Bi}-\mathrm{Fab}$ antibodies showed significant ADCVI activity for three clade B isolates and a clade C isolate (Table 1). There are significant differences in ADCVI activity among the virus isolates and between the different $\mathrm{Bi}-\mathrm{Fab}$ constructs which is not necessarily explained by differences in the immunoreactivity with gp41 and neutrophils by the Bi-Fab molecules. Whereas both molecules were effective at inhibiting $\mathrm{BaL}$ (similar to the chemical conjugate of antibody Fabs), F240 $\times 14 \mathrm{~A} 8 \mathrm{Bi}$-Fab-A was more effective at ADCVI than F240 $\times 14 \mathrm{~A} 8 \mathrm{Bi}-\mathrm{Fab}-\mathrm{B}$ for JR-FL. In contrast, the F240 $\times 14 \mathrm{~A} 8 \mathrm{Bi}-\mathrm{Fab}-\mathrm{B}$ showed much higher ADCVI activity than Bi-Fab-A against 93MW960 and SF162 with the activity of the chemical conjugate intermediate between both of them. These differences may represent a number of mechanistic effects of the structure of both the antibody and the virus. Neither Bi-Fab construct neutralized HIV directly (data not shown).

\section{Discussion}

Building on our previous report of a chemically constructed bispecific antibody directing destruction of $\mathrm{HIV}^{4}$, we have produced molecular HIV specific bispecific antibody molecules incorporating the HIV gp41 specific antibody, F240, and an IgA receptor specific antibody, 14A8. A conventional design was used to link two scFvs for expression as a bispecific scFv. Despite immunoreactivity with HIV (gp41) and neutrophils, this bispecific scFv failed to mediate ADCVI activity. In retrospect, failure of the conventional F240 $\times 14 \mathrm{~A} 8$ biscFv may be predicted by the structure of the biscFv. We hypothesized that failure of the biscFv to mediate ADCVI yet retain immunoreactivity with both HIV and neutrophils may be a function of the structural constraints of the $\mathrm{scFv}$ as compared to the Fab. The longer antibody Fab fragment with the first constant domain of Fc part may allow for more flexibility in bridging the neutrophils and the infected cells.

Viral isolates vary in quaternary structure such that env trimers may range from open to closed. Additional factors include differences in the spatial arrangement of envelope or the glycosylation pattern of viral isolates or the contribution of other membrane components as these studies were performed with HIV infected PBMC. Further studies using mutated viral isolates and crystallography are being designed to explore this. It is also evident that the structure of the bispecific antibody directly impacts function. Consistent with what was observed previously, the heavy chain $\mathrm{CH} 1$ domain can affect antibody binding affinity and fine specificity [11]. A larger, flexible structure conferred by the $\mathrm{CH} 1$ and $\mathrm{CL}$ domains significantly contributes to the action of the bispecific antibodies in inhibiting HIV. Whereas the single chain construct failed to function although it did bind HIV and PMN, a flexible Bi-Fab molecule was able to confer function. Interestingly, the activity of the chemical conjugate of the Fab of antibodies F240 and 14A8 is similar to both Bi-Fabs for BaL but intermediate between Bi-Fab A 
and Bi-Fab B for two other isolates (93MW960 and SF162). This would suggest that the structure or conformation of the variable regions (e.g., natural Fab versus scFv) also impacts function. Finally, it is clearly shown that cross-linking CD89, which occurs outside of the IgA binding site, is active even if CD89 is occupied by $\operatorname{IgA}$ and is a viable option to activate PMN to "inhibit" HIV. There is considerable research demonstrating that cross-linking of $F_{c} \alpha \mathrm{R}$ (CD89) using bispecific antibodies can induce tumor cytotoxicity [12-15], as well as target pathogens, such as Streptococcus pneumonia [16], Porphyromonas gingivalis [17], and Bordetella pertussis [18]. The approach presented in this study is unique for HIV immunotherapy in that the impetus for "neutralization" is to arm and mobilize neutrophils, which do not get infected, to globally destroy HIV and HIV infected cells.

\section{Conclusions}

These results demonstrate that recombinant Fab-like bispecific antibody constructs effectively inhibit HIV. Moreover, the molecular bispecific antibody construct profoundly affects the functional activity of the antibody. The approach presented in this study is unique for HIV immunotherapy in that the impetus of neutralization is to arm and mobilize PMN to destroy HIV and HIV infected cells.

\section{Disclosure}

Current address of Mark Duval, Melissa Gawron, and Lisa A. Cavacini is as follows: MassBiologics, University of Massachusetts Medical School, Boston, MA, USA. Current address of Marshall R. Posner is as follows: The Tisch Cancer Institute, Icahn School of Medicine at Mount Sinai, New York, NY, USA.

\section{Competing Interests}

The authors declare that there are no competing interests related to the publication of this paper.

\section{Acknowledgments}

This work was supported by Public Health Service Grant R01AI076138 from the National Institute of Health.

\section{References}

[1] P. D. Kwong and J. R. Mascola, "Human antibodies that neutralize HIV-1: identification, structures, and B cell ontogenies," Immunity, vol. 37, no. 3, pp. 412-425, 2012.

[2] O. Lambotte, G. Ferrari, C. Moog et al., "Heterogeneous neutralizing antibody and antibody-dependent cell cytotoxicity responses in HIV-1 elite controllers," AIDS, vol. 23, no. 8, pp. 897-906, 2009.

[3] J. Thèze, L. A. Chakrabarti, B. Vingert, F. Porichis, and D. E. Kaufmann, "HIV controllers: a multifactorial phenotype of spontaneous viral suppression," Clinical Immunology, vol. 141, no. 1, pp. 15-30, 2011.

[4] M. Duval, M. R. Posner, and L. A. Cavacini, "A bispecific antibody composed of a nonneutralizing antibody to the gp41 immunodominant region and an anti-CD89 antibody directs broad human immunodeficiency virus destruction by neutrophils," Journal of Virology, vol. 82, no. 9, pp. 4671-4674, 2008.

[5] L. A. Cavacini, C. L. Emes, A. V. Wisnewski et al., "Functional and molecular characterization of human monoclonal antibody reactive with the immunodominant region of HIV type 1 glycoprotein 41," AIDS Research and Human Retroviruses, vol. 14, no. 14, pp. 1271-1280, 2009.

[6] D. M. Fishwild, S. L. O’Donnell, T. Bengoechea et al., "Highavidity human $\operatorname{IgG\kappa }$ monoclonal antibodies from a novel strain of minilocus transgenic mice," Nature Biotechnology, vol. 14, no. 7, pp. 845-851, 1996.

[7] G. R. McLean, A. Nakouzi, A. Casadevall, and N. S. Green, "Human and murine immunoglobulin expression vector cassettes," Molecular Immunology, vol. 37, no. 14, pp. 837-845, 2001.

[8] L. A. Cavacini, J. E. Peterson, E. Nappi et al., "Minimal incidence of serum antibodies reactive with intact primary isolate virions in human immunodeficiency virus type 1-infected individuals," Journal of Virology, vol. 73, no. 11, pp. 9638-9641, 1999.

[9] L. R. Miranda, M. Duval, H. Doherty, M. S. Seaman, M. R. Posner, and L. A. Cavacini, "The neutralization properties of a HIVspecific antibody are markedly altered by glycosylation events outside the antigen-binding domain," Journal of Immunology, vol. 178, no. 11, pp. 7132-7138, 2007.

[10] X. Yu, M. Duval, C. Lewis et al., "Impact of IgA constant domain on HIV-1 neutralizing function of monoclonal antibody F425Alg8," Journal of Immunology, vol. 190, no. 1, pp. 205-210, 2013.

[11] D. Tudor, H. Yu, J. Maupetit et al., "Isotype modulates epitope specificity, affinity, and antiviral activities of anti-HIV-1 human broadly neutralizing 2F5 antibody," Proceedings of the National Academy of Sciences of the United States of America, vol. 109, no. 31, pp. 12680-12685, 2012.

[12] Y. M. Deo, K. Sundarapandiyan, T. Keler, P. K. Wallace, and R. F. Graziano, "Bispecific molecules directed to the Fc receptor for IgA (Fc $\alpha$ RI, CD89) and tumor antigens efficiently promote cellmediated cytotoxicity of tumor targets in whole blood," Journal of Immunology, vol. 160, no. 4, pp. 1677-1686, 1998.

[13] K. Sundarapandiyan, T. Keler, D. Behnke et al., "Bispecific antibody-mediated destruction of Hodgkin's lymphoma cells," Journal of Immunological Methods, vol. 248, no. 1-2, pp. 113-123, 2001.

[14] B. Stockmeyer, M. Dechant, M. van Egmond et al., "Triggering FC $\alpha$-receptor I (CD89) recruits neutrophils as effector cells for CD20-directed antibody therapy," Journal of Immunology, vol. 165, no. 10, pp. 5954-5961, 2000.

[15] F. J. Hernandez-Ilizaliturri, V. Jupudy, J. Ostberg et al., "Neutrophils contribute to the biological antitumor activity of rituximab in a non-hodgkin's lymphoma severe combined immunodeficiency mouse model," Clinical Cancer Research, vol. 9, no. 16 I, pp. 5866-5873, 2003.

[16] W.-L. Van der Pol, G. Vidarsson, H. A. Vile, J. G. J. Van de Winkel, and M. E. Rodriguez, "Pneumococcal capsular polysaccharide-specific IgA triggers efficient neutrophil effector functions via Fc $\alpha$ RI (CD89)," Journal of Infectious Diseases, vol. 182, no. 4, pp. 1139-1145, 2000.

[17] T. Kobayashi, A. Takauchi, A. B. V. Spriel et al., "Targeting of Porphyromonas gingivalis with a bispecific antibody directed to Fc $\alpha$ RI (CD89) improves in vitro clearance by gingival crevicular neutrophils," Vaccine, vol. 23, no. 5, pp. 585-594, 2004.

[18] S. M. M. Hellwig, A. B. Van Spriel, J. F. P. Schellekens, F. R. Mooi, and J. G. J. Van de Winkel, "Immunoglobulin A-mediated protection against Bordetella pertussis infection," Infection and Immunity, vol. 69, no. 8, pp. 4846-4850, 2001. 


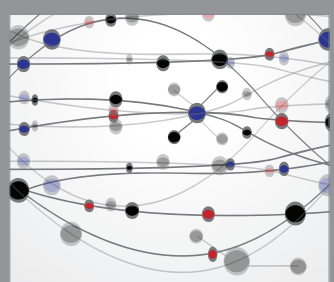

The Scientific World Journal
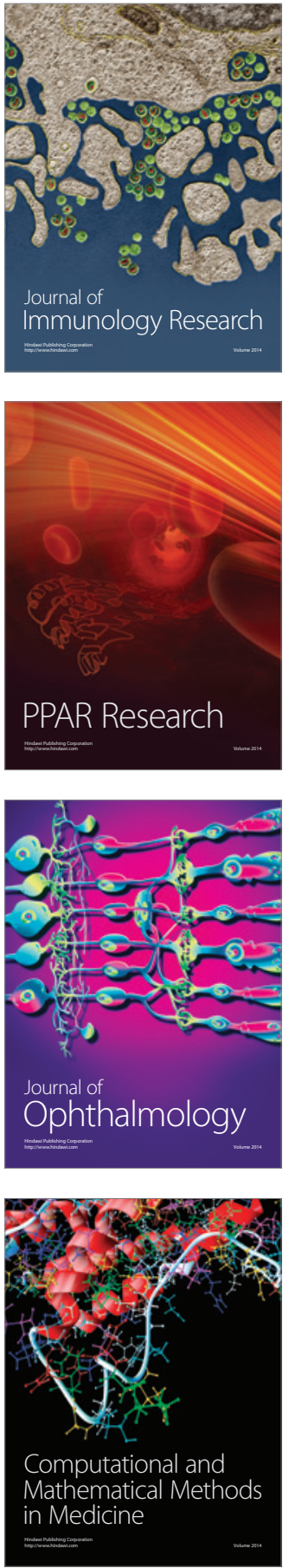

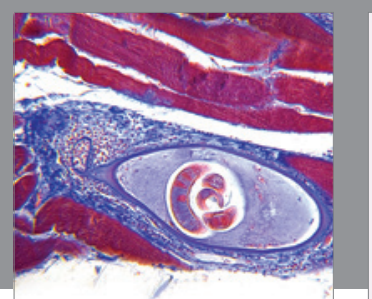

Gastroenterology Research and Practice

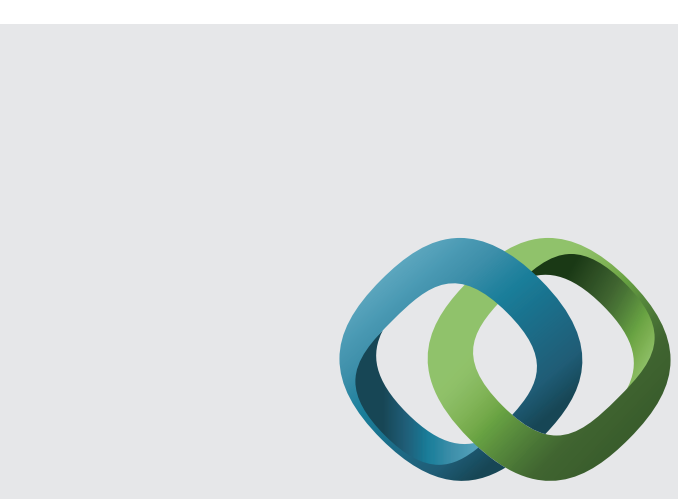

\section{Hindawi}

Submit your manuscripts at

http://www.hindawi.com
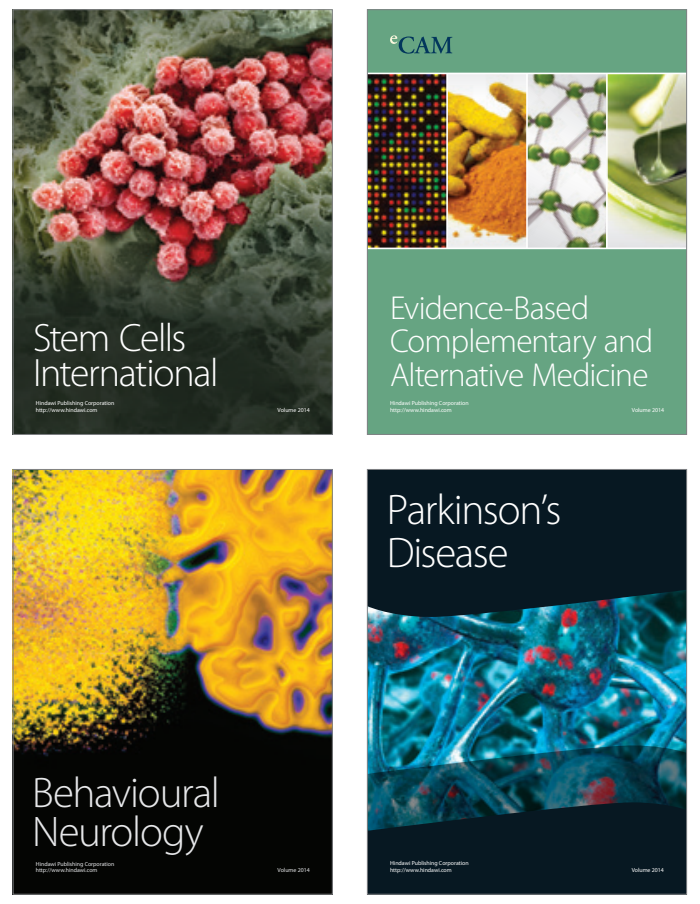
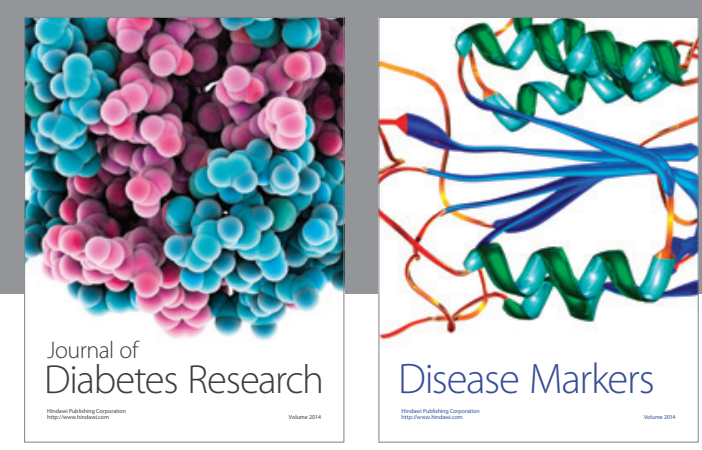

Disease Markers
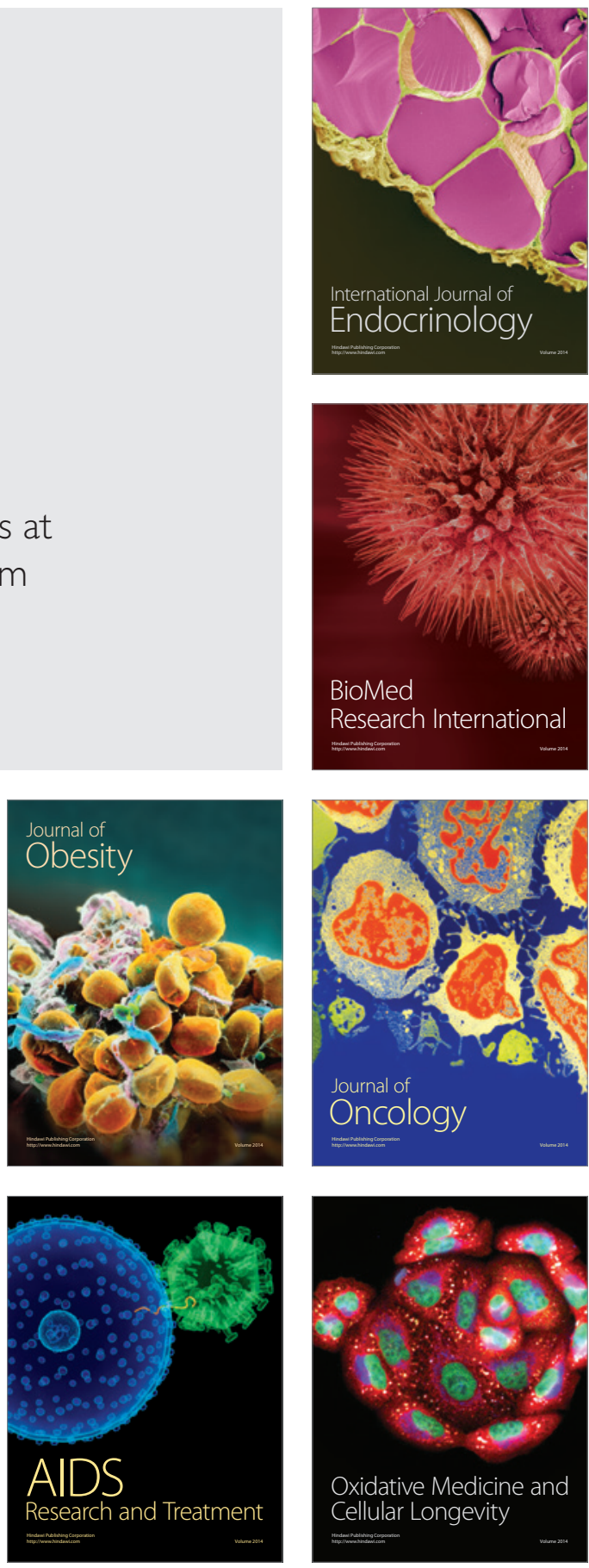